\title{
Innovative Project Methods and Procedures for Implementation of Companies
}

\author{
Vladimír Rudy ${ }^{1, *}$, Norbert Šmajda ${ }^{1}$, Ján Rusnák ${ }^{1}$ \\ Technical University of Košice, Faculty of Mechanical Engineering, Institute of Management, Industrial and Digital Engineering, Park Komenskeho \\ 9,04200 Kosice
}

\begin{abstract}
Designing of today's complex and diverse production systems requires a comprehensive analysis of their operations in three spatial dimensions and over time. Only this approach is a guarantee of identification, optimization, respectively elimination of project disadvantages before their future physical implementation. The designer of tomorrow's production groups must be a professional and a specialist. He must have the creativity and professional theoretical and practical knowledge of the issues that are solved in the project. In technical project solutions, he must have a sense of precision and addressing details as a limiting requirement for the success and implementation of a future project. He must follow the development trends of designing new production structures and the direction of their development and he can't stay at the level of selection the outdated, time-consuming technical solutions and applied technologies.
\end{abstract}

Keywords: designing of new productions, design methodology, modeling, production structure

\section{Introduction}

Adequate methodological procedures, algorithms and tools have been developed for a long time for the design of production systems, which will ensure higher efficiency of solutions in the entire methodological sequence of the solution of a new production project.

In the present busy business environment, production systems of companies must show increased flexibility and permanent ability to cope with dynamically changed market demands for products, their functions and variants. Innovative processes, innovative entrepreneurship and the promotion of innovative culture are generally considered to be key to economic development and are one of the important tools for the prosperity of the company. They are accompanied by activities that lead to successful production and utilization of technical news and knowledge, offer new solutions to problems and enable meeting the needs of individuals or companies. Current development of the means of production leads to the point where individual devices are easy to operate, quickly to adjust, highly automated and flexible. The issue of changing current and future production is characterized by several attributes, but one of the most important is the transition to a knowledge-based society and a new production culture. Priority is the production with high value added and the corresponding knowledge engineering (original products, new production technologies, new production systems, new ways of production organization and management, etc.). The production systems of a company must show increased flexibility and a permanent ability to deal with dynamic requirements of the market with respect to the products, their functions and variants. 
Innovative processes and a general support of innovative culture are the key to development and they are an important prosperity tool. They are accompanied by activities that lead to successful production and use of technical novelties and knowledge. Development of productive resources leads to failure-free machines, with the ability to auto detect failures that are simply controlled, quickly adjusted, highly automatized. The problem of modifying current and future production could be described through many attributes, but the most important aspect is achieving transformation into a knowledgeable society and instilling a new culture of manufacturing. Priority is production that adds the highest value, appropriate knowledge based on engineering (original products, new productive technologies, new production systems, new approaches to production organization and management). Currently, a complete range of different strategies exists describing development of new products, implemented in industrially advanced countries.

From the basic methods that can help develop modern manufacturing, the most important ones are those that greatly accelerate innovation cycles and enable faster and more efficient implementation of process modernization. How to set the company on the path of optimal strategic position and to preserve its competitiveness on the globalized and crisis-prone market of today is a dilemma of many company owners and managers. The solution is in the application of "Industry 4.0" methodologies that are based on SMART technologies, virtual and mixed reality, digitization in the whole spectrum of production processes, collection, sorting and evaluation of relevant data of these processes that depend on the production quality, etc.

The scientific-research and pedagogical activities of the main author have for many years focused on the design of mechanical engineering productions, the application of innovations and the methodologies of designing intelligent productions based on virtual and digital technologies. The co-authors are the PhD. students in the external form of study with a focus on the application of "Industry 4.0" methodologies.

\section{Innovative approaches to designing production system structures}

Engineering production design requires a system solution for a set of structural, technological, spatial and organizational factors resulting in the design of an optimal manufacturing configuration. The goal is the functional integration of people, information, production technology, materials and energy to prevent wasting these resources and to achieve high productivity. The efficiency of operation depends on the level of mutual synchronization, the ability to predict and eliminate adverse effects of these factors on the production characteristics of the production system. So the role of design activity is to design and, in the form of design documentation, to process the production configuration that can be executed under optimal financial conditions in the required space and time, capable to meet time-limited market demands. The final design, taking into account the mutual synergy of these factors and guaranteeing the consistency of designed ideas with the achieved results, leads in practice to the complexity and variability of possible solutions. Capability of reconfiguration or building new innovative productions is, therefore, one of the most complex tasks in the company life cycle. It requires the application of adequate computer, information and software support for modern CAx systems capable to apply standardized design procedures and to modify configurations from "proven" designs.

Innovations in project activities require special knowledge and appropriate methods, procedures and tools. An important role is played by theoretical sciences. The development of engineering work is supported by several engineering disciplines. Design Science (Design Theory, Design Philosophy) is important because it contains a set of logically clustered knowledge about solutions generated by engineering activities. Designing is a complex area of theories, methods and information, including a broad field of engineering activity. The knowledge base of design team members can be divided into:

- General and special knowledge of technical systems and processes, including the manner of their expression, characteristics and quality, structures and principles of their development,

- General and special knowledge of engineering design, its structure, features, characteristics and management,

- Special, detailed, design-necessary knowledge of the technical, technological, economic, organizational and control nature of the aspect of design,

- Managerialskills in the field of design management and teamwork.

Designing today's manufacturing systems requires a comprehensive analysis of their activities 
in real space and time. Only this approach is a guarantee of identification, optimization, or elimination of design deficiencies before their future physical implementation. It is necessary to take into account the philosophical aspects of technological innovations, modeling, examples and studies of successful reference solutions, financial support and material provision for innovative changes, multi-purpose and purpose-oriented designs for the synthesis of technological innovations, etc. The frame methodology of application designated for the assembly of the production structure model is illustrated in Fig.1. It takes place in four stages:

1. Creation of knowledge base and its analysis (in accordance with customer requirements).

2. 2D / 3D variant modeling - spatial optimization of the system's structure.

3. Optimal production structure - functional simulation of the virtual production model.

4. Production of design documentation, GIS modification of the production model and its implementation.

Concepts of new production systems are currently designed as the systems of new generation. The aim of such solutions is to increase productivity without losing flexibility, shortening production time, increasing the quality and the value of products and services, and so on. They are modified as social and economic systems and place high demands on design, implementation and operation. The numerous papers in professional literature deal with their development.

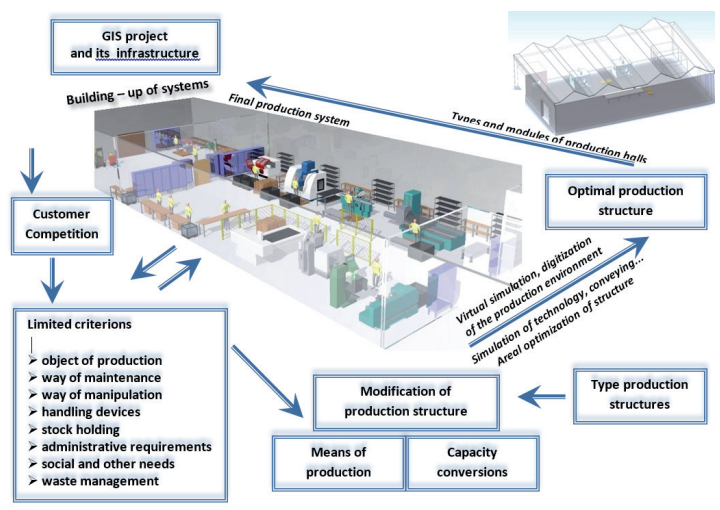

Figure1: Design procedure characteristics of new production structure their development.

Combination of SW applications with HW of 3D type beamers, cameras, 3D scanners, digitizers, etc., enables the future real image of the production system to be interpreted in virtual reality and by that:

- itreveals critical deficiencies before the real system implementation, - simulates the functional activity of system elements, i.e. verifies dynamic properties of static objects (e.g. the course of technological processes, movement of workers, flow of material).

- Simulation of the processes of the proposed manufacturing assemblies means:

» a thorough analysis of CAE variants of generated structures and the complexity of their assessment as a result of a multidisciplinary solution,

» application of prototype and the already existing knowledge databases enabling reuse of the data,

» verification of the use of already approved analysis procedures, etc.

" data management and effective handling of large data amounts related to simulation including solution parameters and results,

" correction of functional visualization of the means of production of the real production model,

» high consistency of the design with the real production model (objectivity of the virtual reality model),

„ on-line back-up design correction, etc.

The current market offers application software systems that support manufacturing system design in different application areas. The use of such systems allows to design the entire production system, to purposely situate the means of production in the production area, to design traffic paths, storage areas, to make their simulation, to display and describe them from any views, etc.

Current development enables these different approaches to be included in a single integrated system. Synchronous work in real and virtual environments brings a number of effects. Integrated procedures ensure that all actions applied to real physical models are transferred to parallel work with computer models that are subsequently presented in virtual environment.

An important innovative method of designing production systems is simulation and its methods, techniques and tools. Managing simulation means: - a thorough analysis of CAE variants of generated structures and the complexity of their assessment as a result of a multidisciplinary solution,

- searching and application of prototype, already existing knowledge databases enabling data re-use,

- in combination with supportive process algorithm procedures, it enables the verification of the use of already approved analysis procedures, etc. 
- visualization of simulation results of the time cycle of simulated action in a specific environment.

- the reliability and confidence of the reality of the results obtained and the possibility of online feedback on the development, or design status.

The key role in terms of speed and flexibility of project activities, in addition to adequate $\mathrm{SW}$ tools, is played by the existence of databases of production, handling and peripheral technology. An example of the content of manufacturing technology database is illustrated in Fig. 2.

Models of virtual reality enable:

- replacement of physical prototypes with virtual ones,

- improvement and acceleration of the product development processes,

- simulation of different development stages in virtual environment.

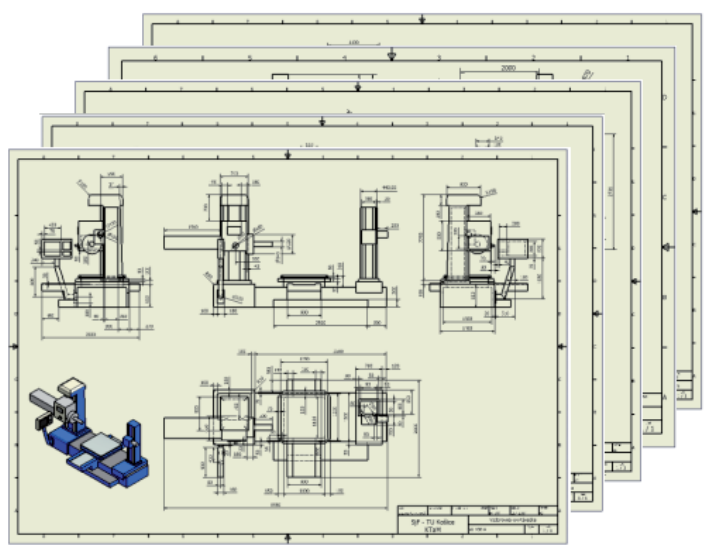

Figure 2: An example of catalogue sheet from the production machinery database.

In virtual environment there are applied in engineering production:

- Process planning (production layout, time analyses, technological preparation of production, product evaluation, cost analyses, etc.).

- Replacing physical prototypes with virtual ones,

- Improving and accelerating the product development processes,

- Simulating different development stages in virtual environment

- Processing details and validation (production and maintenance, welding, assembly procedures, cell and factory layouts, manufacturing operations, employee performance, etc.).

- Modeling and resource simulation (material flow simulation, robotic cell type pre-specification, NC machining, virtual reality scenarios, ergonomic analyses, etc.).

- Automation and Control (Control Logic, Programming, Robots,)

The company's digital configuration is conceptually formed by integrating three basic building elements - product with its static and dynamic properties, production planning and the production itself with the possibility of using planning data to increase process efficiency.

(Digital Factory) is mainly used in engineering, automotive, aviation, electrotechnical and shipbuilding industry and in the manufacture of industrial goods [1], [3], [7], [8].

The digital enterprise serves the purpose of planning, analysing, simulating and optimizing the complex product manufacturing. The approaches used in the environment of digital enterprise cover the four most important areas:

- Process planning (production layout, time analyses, technological preparation of production, product evaluation, cost analyses, etc.).

- Process detail and validation (production and maintenance, welding, assembly procedures, cell and plant layouts, manufacturing operations, employee performance, etc.).

- Modeling and resource simulation (material flow simulation, robotic cell type pre-specification, NC machining, virtual reality scenarios, ergonomic analyses, etc.).

- Automation and control (control logic, programming of production technology, etc.).

\section{Production systems supported by design using virtual reality}

To accelerate and streamline a designer's work, a variety of tools in the classic design of production systems have already been designed and manufactured for processing especially the last stage of technological design - an image of spatial layout.

Currently, the most widely used method of technology design imaging is a two-dimensional (2D) or three-dimensional (3D) model. With 2D imaging, the individual production machines, handling, transport, storage and other devices are shown in the selected model scale based on actual ground dimensions. An important parameter is the range, the range of motion of the moving parts of the machinery, and appropriate labelling Graphic design of production technology in three-dimensional space is made in a plane, front elevation, and side elevation. In classic design this is a "labour intensive" activity. The front elevation always shows only one cross-section. When showing multiple cross-sections, a problem with displaying the respective relations arises.

Recently, an analysis of production processes or entire processes in three spatial dimensions have become required. An appropriate technical 
aid in this case is a spatial model, i.e. a reduced symbolic image of the production machine or the whole production system. It can be a model of an individual device or a model of the whole in the form of an illustration, installation, construction, teaching or architectural model. The advantage of these models is their clarity.

Using 3D models is appropriate if the drawings clearly cannot define and illustrate the design section of the proposal. At the same time, the routine part of design drawings is eliminated and the creative aspect of the designer's work is unleashed. The 3D model of a workstation can detect collision circumstances in the primary stage of the solution that would otherwise overload the total solution due to optimizing deviations from the original state after the implementation of the selected solutions have been made and such deviations have been discovered.

Today, the state-of-the-art innovation trends are models of virtual reality. The aim of the virtual reality (VR) systems is to provide users or a group of users collaborating together with an illusion that they are in an artificial environment, called virtual world, virtual scene or virtual environment.

The basis for virtual reality are procedures creating spatial models and scenes where those models can be toyed with, moved in three-dimensional space and displayed in real time. Using special peripherals to deliver video, audio and tactile interactions, virtual reality brings extraordinary experiences and brings about new and unexpected possibilities to computer technology applications. Virtual reality applications have the following characteristics:

- actions occur in real time,

- scenes and objects are three-dimensional or create an illusion of being so,

- the user can enter the scene and move through it,

- the scene is not static; the user can interact with its objects.

Virtual Reality enhances the distribution of imaging techniques in computer graphics in two ways. The first aim is rapid creation of an image and the second objective is to create a realistically looking object. Modeling and 3D imaging is an irreplaceable area of design dealing with the creation of production systems and with their implementation into nowadays largely utilized CAD systems. The computer graphics is the basis for virtual reality processes, namely for creation of spatial models and scenes, interacting with them, moving in three-dimensional space, detecting collisions and real-time display. These methods are enhanced by the use of peripherals that provide video, audio and tactile interaction. In particular, these are the helmets with built-in screens, stereoscopic projection screens, position sensors in space, tactile devices, simulation cabins, etc. [4].

Virtual reality models allow to:

- replace physical prototypes with virtual ones,

- simulate various stages of development in virtual environment,

- improve and accelerate the product development and other processes, etc.

The purpose of virtual reality is that the virtual environment can be shared by many users at once, and allows them to interact with each other. In this way, several people can work together to solve problems. Examples of SW outputs of production structure projects are illustrated in Fig. 3 to Fig. 5.

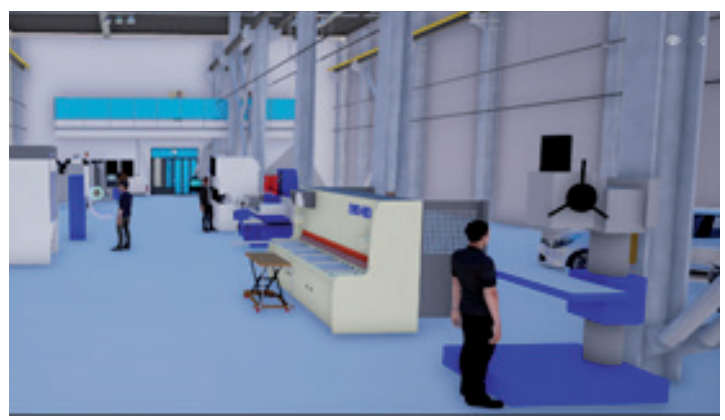

Figure 3: Example outputs of solutions for production configuration designs.

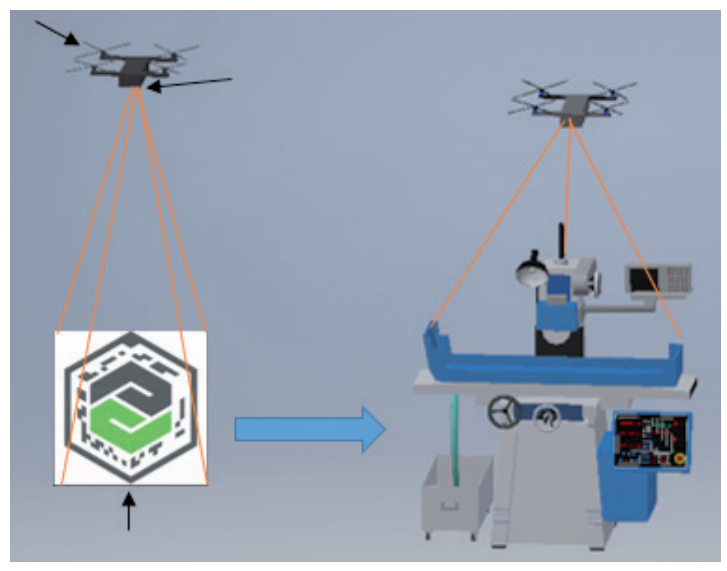

Figure 4: Creation of the production structure of the workplace by means of holographic projection. 

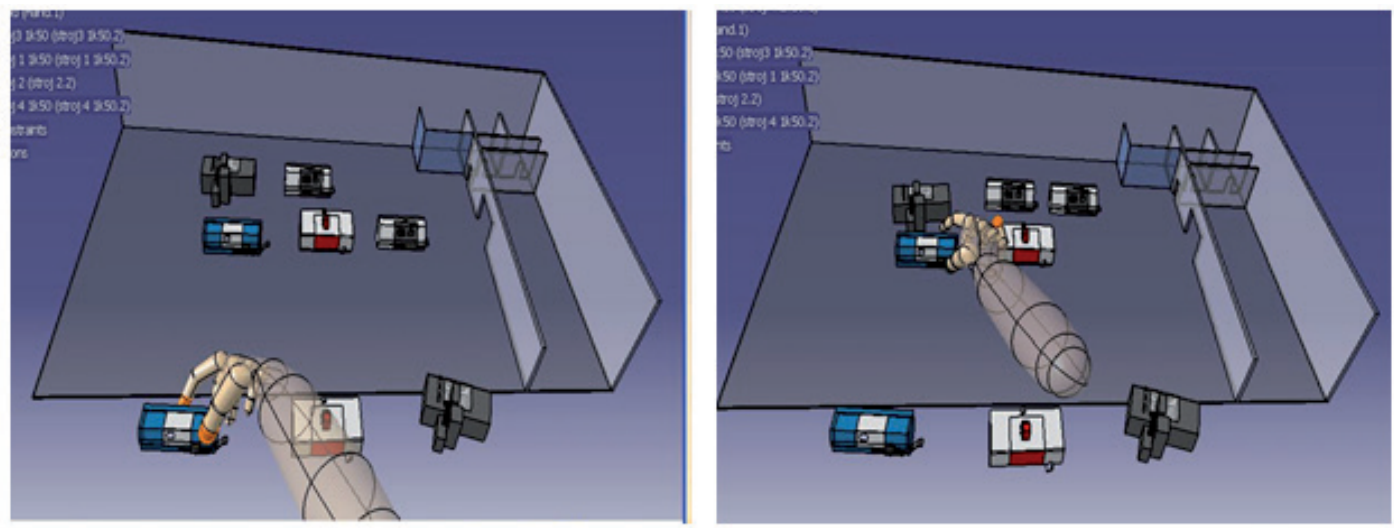

Figure 5: Example of spatial handling principle 3D models of the means of production

\section{Conclusion}

As a breakthrough technology, virtual reality (VR) enables to enter 3D simulated worlds through technical and software tools. Virtual reality is characterized by the ability to provide interactivity and "immersion" in the user environment.

Features of virtual reality are new types of virtual technical means, such as 3D imaging units, data gloves, 3D glasses, head displays, 3D beamers and other devices. The interactive way of working characteristic for virtual reality increases the user's sense that through these means and appropriate software he acts in a real environment. However, interactivity in real environment can also be performed by the classic Input / Output units (mouse and keyboard, etc.) and does not require special hardware or virtual accessories. In the applications where VR is used to visualize and simulate dynamic behaviour of technical objects or designed processes and systems, perceiving these processes in 3D environment is necessary and it poses a significant benefit of virtual technologies.

Laboratory application of virtual technologies currently includes training, operator training, prototype testing of technical objects (in particular products), graphic display of product data and lists, simulation and animation of production processes and systems (e.g. assembly, dismantling, maintenance of equipment, etc.) ergonomic studies as well as entertainment. By using virtual reality, an artificial virtual environment can be created in such a way that it convinces the user to think it is real. Complicated production processes performed by complex machines can be complemented by $3 \mathrm{D}$ details displaying their internal structure, and so on. The high investment and operating costs of setting up advanced "immersive" virtual reality systems (CAVE, CUBE, etc.) out of reach for a large part of the users have led to development of desktop applications that can be implemented by $P C$ systems, or portable computers. These, in collaboration with the technical means of virtual reality and software systems, are an important alternative for a large number of users.

This direction of research carried out in the design of production processes and systems is suitable for small and medium-sized enterprises. From technical point of view several types of devices and units can be used in such design systems: the Cyber Glove II Data Glove, the Flock of Birds, the 3D touch systems (Computer Aided Sculpting (CAS)), the Trackball (Space Pilot), the Motion Transfer Devices (Ascension Flock) and more.

\section{This article was created by implementation of the grant project KEGA 002TUKE-4/2020 Implementation of intelligent technology and advanced technologies to support transformation processes and future product design.}

\section{Bibliography}

[1] Bubeník, P., Bubeníková, E., Korbel, P., Nagy, P.: Information Technology for Business Practice. Edis, ŽU in Žilina, 2004, ISBN 80-8070-288-8

[2] Kovač J., Rudy V., Kováč J.: Methods for the design of production processes. Specifics of designing production systems. Edition of professional and scientific literature. TU UK Košice. 2017.326 p. ISBN 978-80-553-2874-4

[3] Kovač J., Rudy V., Kováč J.: Methods for the design of production processes. Innovative design of production systems. Edition of professional and scientific literature. TU UK Košice. 2017.326 p. ISBN 978-80-553-2873-7

[4] Kováč, J., Rudy, V., Kováč, Juraj: Automation of production. 
Edition of scientific and professional literature. SjF TU in Košice. 2016. ISBN 978-80-553-2311-4

[5] Kováč, M., Kováč, J : Integrated Production. ES VŠT Košice, 1990

[6] Daneshjo, N., Malega, P.: Improvement Project of Production Line Using Automation. 2020.In: TEM Journal : Technology, Education, Management, Informatics. - Novi Pazar (Srbsko): Association for Information Communication Technology Education and Science Roč. 9, č. 3 (2020), s. 1003-1010 [print, online]. ISSN 2217-8309

[7] Micieta B., Edl M., Krajcovic M., Dulina L., Bubenik P. Durica L., Binasova V.: Delegate MASs for coordination and control of one-directional AGV systems: a proof-of-concept.

[8] Rudy, V., Malega, P.: New approaches to construction production layout, 2020. In: Invent 2020: 16.9.2020: Žilina, S. 128-131, Žilina : Žilinská univerzita v Žiline, 2020 /978-8366249-48-6

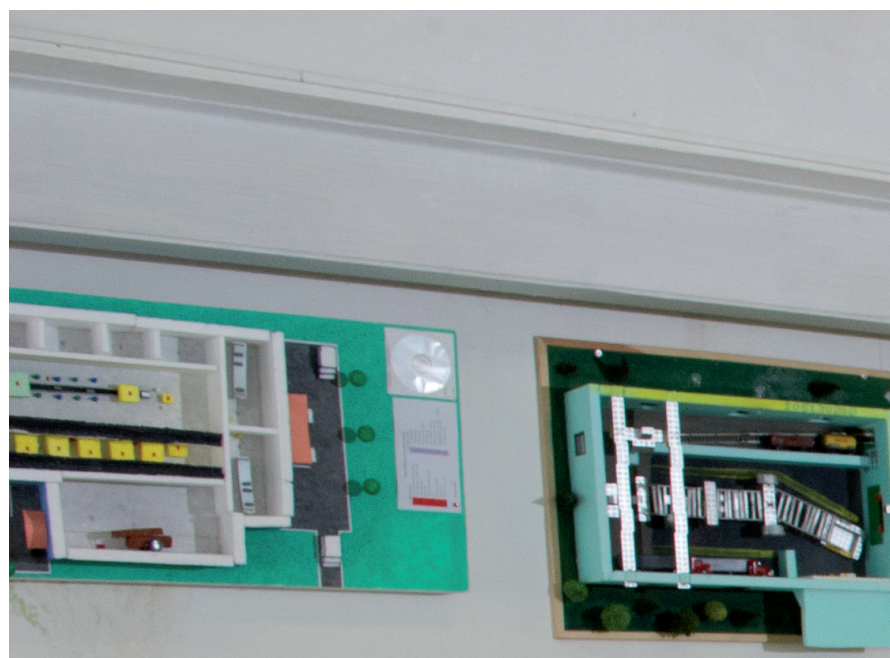

